\title{
Transfer Effects of Working Memory Intervention on Linguistic Abilities in Patients with Dementia
}

\author{
Mi Sook Lee', Bo Seon Kim² \\ 'Department of Audiology and Speech-Language Pathology, Hallym University of Graduate Studies, \\ HUGS Center for Hearing and Speech Research, Seoul, Korea \\ ${ }^{2}$ Seoul Asan Rehabilitation Clinic, Incheon, Korea
}

Received: September 24, 2019 Revised: October 25, 2019

Accepted: November 13, 2019

Correspondence:

Bo Seon Kim, PhD

Seoul Asan Rehabilitation Clinic, 818 Hogupo-ro, Namdong-gu,

Incheon 21534, Korea

Tel: +82-32-466-7582

Fax: +82-32-466-7581

E-mail: bskimslp@gmail.com
Purpose: Working memory training for Alzheimer's disease (AD) patients may yield everyday cognitive-linguistic benefits by facilitating transfer effects in multiple domains. The purpose of this study was to investigate the effects of working memory intervention and differences on transfer effects in type of intervention paradigm like core training (CT) and strategy training (ST). Methods: A total of 24 patients with mild and moderate $A D$ were divided into $C T$ and $S T$ group ( $n=12$, respectively). After CT and ST interventions, we assessed their transfer effects on linguistic abilities including reading comprehension, figurative language, word fluency, and discourse production. Results: There were three main findings. Firstly, CT group improved significantly in figurative language, word fluency, and discourse production. Secondly, ST group showed the significant intervention gains in figurative language and discourse production. Thirdly, CT group had higher transfer effects in figurative language and discourse production than ST group, while both were similar in other transfer effects. Conclusion: This study proves that effects of working memory intervention for AD patients are different in type of paradigm, and thereby presents a roadmap for increasing the efficacy and utilization of working memory intervention in clinical settings.

Key Words: Working memory training, Alzheimer's disease, Transfer effects, Paradigm, Linguistic abilities.

\section{INTRODUCTION}

작업기억(working memory)은 복잡한 인지 처리를 위해 필 요한 표상에 일시적으로 접근하는 인지 체계이다(Klingberg, 2012). 즉 일상생활의 다양한 과제에서 정보를 보유하고 단기적 으로 저장하거나 조작하는 데 관여하는 핵심 능력이다(Peach $\&$ Shapiro, 2012). 작업기억의 용량(capacity)은 개인에 따라 다 양한데, 지능을 포함한 여러 인지 능력과 상관성이 매우 크다 (Conway et al., 2003).

작업기억의 결함은 다양한 인지 및 의사소통 문제를 초래한 다. 다영역 체계인 작업기억 용량이 제한되면 정보를 임시로 저 장하거나 처리들 간에 주의력을 분산시키는 데 어려움을 겪는 다. 이로 인해 주의력의 할당과 선택, 억제, 정보의 업데이트와 같은 집행기능이 제대로 발휘되지 못한다(Lezak et al., 2004).

(c) This is an Open Access article distributed under the terms of the Creative Commons Attribution Non-Commercial License (https://creativecommons.org/licenses/by-nc/4.0) which permits unrestricted non-commercial use, distribution, and reproduction in any medium, provided the original work is properly cited.
특히 새로운 상황에 효율적으로 적응하기 위한 유동성 지능 (fluid intelligence)에 영향을 주고, 문제 해결력, 추론력 등의 고 차원적 인지, 언어 학습 능력에 광범위하게 관여한다(Kane et al., 2004).

작업기억 용량이 제한적일수록 읽기 및 듣기 이해, 계산 능력, 언어 처리 속도 등 전반적인 언어 처리 능력이 저하된다(Borella et al., 2008). 언어 표현에 대한 작업기억의 영향도 뚜렷한데, 특 히 자발화의 유창성, 문법적 복잡성, 구어 능력 등에 크게 관여 한다(Peach \& Shapiro, 2012). 작업기억의 저하로 의미망(semantic network)에 저장된 단어 및 관련된 의미 자질을 빠르고 정확히 처리하거나 산출할 수 없으면 단어 정의하기 능력이 떨 어진다(Chow et al., 2008). 또한 언어의 의미와 구문, 화용 능 력을 통합적으로 반영하는 담화 과제는 작업기억에 크게 의존 한다(Borella et al., 2008). 따라서 작업기억이 낮을수록 담화 에서 정보 전달의 적절성과 의사소통의 효율성이 낮아진다.

알츠하이머병(Alzheimer's disease, $\mathrm{AD}$ )은 초기 단계부터 작 업기억의 결함이 나타난다(Lee \& Kim, 2019; Peach \& Shap- 
iro, 2012). $\mathrm{AD}$ 의 작업기억이 손상되면 일상생활 전반의 기능 이 떨어지고, 특히 작업기억의 집행 통제(executive control) 영 역은 $\mathrm{AD}$ 의 진행(progress)에 매우 민감하다(Belleville et al., 2007). 언어 측면에서는 복잡한 구문의 의미와 형태를 이해하 기가 어렵고(Bier et al., 2008), 음운적 및 의미적 단어유창성이 나 대면이름대기 능력이 낮아진다(Lee \& Kim, 2019). 작업기 억의 결함을 민감하게 반영하는 담화 산출은 연령과 상관없이 지속적으로 저하되었다(Kim \& Lee, 2019).

정신 활동의 핵심 영역이자 다양한 인지-언어 처리의 결정 인자로서 작업기억의 역할이 부각되면서 이에 대한 중재 및 그 효과성에 주목하는 추세이다(Kane et al., 2004). 작업기억 용 량은 개인에 따라 제한적이나, 구조화된 훈련을 통해 충분히 확 장될 수 있기 때문이다(Westerberg et al., 2007). 실제로 작업기 억 중재를 통해 인지-언어의 주요 기능들이 광범위하게 향상된 다는 보고가 많다(Chein \& Morrison, 2010).

작업기억에 관한 구조화된 정신 활동, 즉 특정한 작업기억 중 재의 패러다임이나 접근법은 인지-언어 능력에 대한 중재 효과를 예측하는 주요 변인이다. 특히 작업기억이 단기 및 장기 기억 기 제와 전반적으로 연관된다는 최근의 견해들을 고려할 때 $(\mathrm{Bad}-$ deley, 2009), 중재의 효과성을 높일 수 있는 패러다임을 적용 하는 것이 중요하다.

작업기억 중재의 패러다임 및 그 효과성에 관해서는 견해가 다양하다. 작업기억의 처리 과정이나 용량의 제한성 등을 설명 하는 모델이나 관점이 다르기 때문이다. 예를 들어 처리 과정을 기준으로 작업기억이 장기기억과 별개의 임시 영역에서 처리된 다는 다중저장(multistore) 모델, 모든 정보가 하나의 기억 체계 내에 집결된다는 단일저장(unitary store) 모델 등이 있으며 (Nee et al., 2008), 이들에 따라 적용 가능한 중재 패러다임이 상이하다. 작업기억 용량의 기준을 기억에 활용할 수 있는 공간 (slot)의 수로 보는 견해와 용량 자체로 보는 견해에 따라서도 중재 방식이 다르다.

흔히 작업기억 중재 패러다임을 고려할 때 두 하위 요소에 기초하는 경우가 많다. 즉 영역 일반적(domain-general) 또는 집행적 요소와 영역 특수적(domain-specific) 요소로서, 이들 은 모두 작업기억과 고차원적 인지를 연결하는 데 기여한다 (Kane et al., 2004). 영역 일반적 요소는 특정 유형의 정보나 감 각 양식과 무관한 방식으로 처리되며, 작업기억으로부터 정보 의 부호화와 유지, 인출을 지원한다. 또한 주의력을 통제하고 작업기억 완충기(buffer)의 안팎으로 정보의 흐름을 전달하며, 무관한 정보원으로부터 방해를 감소시킨다. 반면에, 세부적인 전략과 연관된 영역 특수적 요소는 특정 형태의 정보를 유지하 고 다루는 데 관여한다(Morrison \& Chein, 2011). 예컨대 언어 적 또는 부호화된 구어 항목의 표상을 유지하기 위해 내적 언 어(inner speech) 기제를 활용하는 조음 암송(articulatory rehearsal)이 이에 해당한다. 영역 특수적 요소에 비해 집행적 주 의력의 처리에 깊이 관여하는 영역 일반적 요소는 고차원적 인 지 기능의 주요 지표로 간주된다. 영역 특수적 요소가 작업기 억의 여러 하위 처리에 영향을 주는 반면, 영역 일반적 요소에 기반한 중재는 광범위한 일반화 효과를 갖기 때문이다.

핵심 훈련(core training, $\mathrm{CT}$ ) 패러다임은 영역 일반적 작업기 억 기제에 기초하며, 영역 특수적 전략의 사용을 제한하고 자동 화된 반응을 최소화하는 데 중점을 둔다(Morrison \& Chein, 2011). 다양한 양식이 활용된 과제와 자극으로 구성되고, 방해 의 제어와 빠른 부호화, 인출 요구가 강화된다. 따라서 CT 패러 다임을 통해 다양한 수준의 능력에 적응할 수 있다. 예컨대 CT 의 과제는 주로 순차적 처리 및 기억력 업데이트가 포함된다 (Olson \& Jiang, 2004). 작업기억 체계의 다양한 구성 요소와 자극 유형을 결합하기 때문에 전이 효과(transfer effect)가 크 며, 특히 읽기 이해, 인지 통제, 추론력, 일화기억 등을 향상시킨 다(Chein \& Morrison, 2010). 그러나 여러 층위의 과제, 자극, 처리가 혼재되어 있어 작업기억 기제 중 어느 요소가 훈련 효 과에 기여했는지를 규명하기 어렵다.

전략 훈련(strategy training, ST) 패러다임은 부호화, 유지, 작 업기억으로부터의 인출에 효과적이며, 정보의 보존을 요하는 과 제의 수행력을 증가시키는 데 목표를 둔다(Morrison \& Chein, 2011). 예컨대 조음 암송에 의존하거나 관련 기술을 증진하는 과제, 정교한 부호화를 촉진하는 청킹(chunking) 과제, 목록과 관련된 심적 이야기를 구상하는 과제, 목록을 기억하도록 심상 (imagery)을 활용하는 과제 등이 ST 패러다임에 해당한다 (Carretti et al., 2007; St Clair-Thompson et al., 2010). 이들은 주로 기억력을 촉진하는 기술을 활용하는데, 과제와 관련된 정 보를 전략적으로 부호화하고 의미지식(semantic knowledge) 등 장기기억 속에 저장된 정보들 간의 상관성을 부각시킨다. 따 라서 ST는 작업기억 기제 자체의 용량이나 효율성을 직접적으 로 증진하기보다 작업기억의 한계를 회피하는 방식을 취하므로 엄밀한 의미에서 작업기억 훈련이라고 볼 수 없다(Morrison \& Chein, 2011). 그러나 최근에는 작업기억의 수행력을 높이기 위 해 보다 직접적인 목표를 취하기도 하며, 특정 작업기억 모델에 대한 구분이 모호해지고 있다.

ST의 효과성에 대한 견해는 다양하다. 일상적인 맥락(예: 수 학 문제의 해결 단계를 구상하기, 요리법을 떠올리면서 쇼핑하 기)을 활용한다는 차원에서 기능적인 효과성이 입증되거나, 다 양한 과제로의 전이 효과도 보고된 바 있다(Carretti et al., 2007), 그러나 특정 기억 전략에 대한 의존도가 높아 훈련 과제에 국한 된 근전이(near transfer) 효과만 나타나고, 상관성이 먼 영역에 대한 원전이(far transfer) 효과가 미미하다는 견해도 있다(St 
Clair-Thompson et al., 2010).

인지-의사소통의 핵심 영역이자 다양한 처리 과정의 결정 인 자로서 작업기억이 갖는 중요성에도 불구하고, 이에 대한 적극 적인 중재나 그 효과성에 대한 검토는 아직 미미한 실정이다. 특히 치매와 같은 신경병리학적 질환의 경우 작업기억 중재를 통해 다양한 전이 효과를 촉진할 수 있고, 일상적인 맥락에서 활용 가능한 인지-의사소통 기능을 향상시킴으로써 삶의 질에 기여할 수 있다. 이에 본 연구에서는 $\mathrm{AD}$ 환자에게 작업기억 기 제에 근거한 두 훈련 패러다임, 즉 $\mathrm{CT}$ 와 $\mathrm{ST}$ 를 적용하여 그 효 과성을 검토하고 차이를 비교하고자 한다. 구체적인 연구 문제 는 다음과 같다.

첫째, 다른 유형의 작업기억 중재 패러다임이 적용된 두 $\mathrm{AD}$ 집단에서 과제별로 중재 전후의 차이가 있는지를 알아본다.

둘째, 전이 효과에 대한 두 집단 간의 차이를 비교함으로써 작업기억 중재 패러다임의 유형이 언어 능력에 대한 전이 효과 에 영향을 미치는지 검토한다.

\section{MATERIALS AND METHODS}

\section{연구 대상}

본 연구는 경도에서 중등도의 $\mathrm{AD}$ 환자 총 24 명을 대상으로 실시하였다. 이들은 서울시 소재의 데이케어센터와 요양병원, 대학 부설 언어재활센터로부터 표집되었다. 신경과 전문의가 National Institute of Neurological and Communicative Disorders and Stroke and Alzheimer's Disease and Related Disorders Association (McKhann et al., 1984)의 기준에 따라 $\mathrm{AD}$ 로 진단하였으며, Clinical Dementia Rating (CDR) (Morris, 1993) 척도에 따라 경도 $(\mathrm{CDR}=1)$ 나 중등도 $(\mathrm{CDR}=2)$ 로 분류된 자들로 제한하였다. 이들은 최소 6년 이상의 교육을 받 은 자들이었다.

중재 방법에 따른 전이 효과를 비교하기 위해 중증도, 인구 통계학적 변인을 고려하여 대상군을 각각 12 명씩 CT 집단과 ST 집단으로 분류하였다. 연령, 성별, 교육 연수, Korean MiniMental State Examination (K-MMSE)의 분포에 대한 동질성 검정을 시행한 결과 연령 $(\mathrm{F}=0.234, t=-1.061, p=0.633)$ 및 성 별 $\left(\chi^{2}=0.000, p=1.000\right)$, 교육 연수 $(\mathrm{F}=0.269, t=0.154, p=$
0.609), K-MMSE (F $=0.680, t=0.901, p=0.419)$ 의 분포상 유 의미한 차이는 없었다.

연령, 성별, 교육 연수, $\mathrm{K}-\mathrm{MMSE}$ 의 평균 및 표준편차 등 두 집단의 인구통계학적 특성은 Table 1에 제시하였다.

\section{연구 도구}

\section{사전-사후 평가}

사전-사후 평가는 중재 전후에 각각 1 회기씩 진행하였다.

중재 전후의 작업기억 능력을 평가하기 위해 단어 폭 검사 (word span test)와 숫자 폭 검사(digit span test)를 시행하였다. 단어 폭 검사는 Sung(2011)의 단어 지시하기 과제(pointing task) 에 사용된 자극을 단어 바로 따라말하기(word forward) 및 거 꾸로 따라말하기(word backward)에 적용하였다. 숫자 폭 검사 는 Korean-Wechsler Adult Intelligence Scale (Yeom et al., 1992)의 하위 검사인 숫자 바로 따라말하기(digit forward) 및 거꾸로 따라말하기(digit backward)를 활용하였다. 단어 폭 및 숫자 폭의 바로 따라말하기는 3 9개, 거꾸로 따라말하기는 2 8 개의 단어 및 숫자 목록으로 각각 구성되어 있다.

언어 능력은 작업기억과의 상관성, 인지 능력을 예측하는 언 어 과제를 고려해 총 4 개 하위 영역을 평가하였다. 즉 $\mathrm{AD}$ 의 작 업기억 용량은 의미적 및 음운적 단어유창성, 읽기 이해와 유 의미한 상관성을 보인다(Lee \& Kim, 2019; Peach \& Shapiro, 2012). 또한 신경학적 기전으로 인한 인지-언어적 변화에 있어 단어유창성, 비유언어 이해 및 표현, 화용언어는 기억력을 포함 한 인지 능력의 주요 예측변인에 해당한다(Lee, 2017).

읽기 이해는 총 2 개 문항으로, 관형절이 포함된 안은 문장과 종속적으로 이어진 문장으로 구성되어 있다. 비유언어는 이해 영역 3 개, 표현 영역 1 개 문항으로 평가하였다. 이해 영역에는 속담, 직유, 관용구에 대한 해석이 포함되며, 표현 영역은 설명 에 해당하는 속담을 문장으로 나타내는 과제이다.

단어유창성을 평가하기 위해 의미적 및 음운적 단어유창성 과제를 시행하였다. 의미적 단어유창성은 '과일' 범주에 해당하 는 단어를, 음운적 단어유창성은 'ㄱ'으로 시작하는 단어를 산 출하도록 하는 과제이다. 전자는 범주의 속성, 특히 생물과 무 생물 범주에 따른 수행력의 차이를 고려하여 '생물' 범주를 활

Table 1. Demographic characteristics in two groups

\begin{tabular}{lcccc}
\hline \multicolumn{1}{c}{ Characteristic } & CT group $(\mathrm{n}=12)$ & ST group $(\mathrm{n}=12)$ & $t$ or $\chi^{2}$ & -1.061 \\
\hline Age $(\mathrm{yr})$ & $76.83( \pm 4.67)$ & $78.92( \pm 4.94)$ & 0.000 & 0.633 \\
Gender (m:f) & $4: 8$ & $4: 8$ & 0.154 & 1.000 \\
Education level (yr) & $9.33( \pm 2.84)$ & $9.17( \pm 2.44)$ & 0.901 & 0.609 \\
K-MMSE & $17.08( \pm 4.19)$ & $15.42( \pm 4.85)$ & 0.419 \\
\hline
\end{tabular}

CT: core training, ST: strategy training, K-MMSE: Korean Mini-Mental State Examination 
용하였고(Laws et al., 2007), 후자는 한국 성인의 구어 및 사전 표제어상의 음소 빈도에 근거하여 선정하였다(Kang et al., 2000; Shin, 2008; Shin, 2010). 담화 능력은 '이야기 다시 말하 기' 과제로 평가하였다. 네 문장으로 구성된 구를 들은 후 내용 을 다시 말하도록 유도하는 과제이다.

사전-사후 평가에 활용된 평가 항목은 Table 2에 요약하였다.

\section{작업기억 중재}

작업기억 중재의 패러다임에 따라 CT와 ST 집단으로 나누 어 시행하였다.

CT 집단의 중재를 위해 작업기억의 각 기제별 하위 과제들로 구성된 3단계의 패러다임을 적용하였다. 이는 Zimmermann et al.(2014)의 작업기억 중재 프로그램을 참조하여 본 연구의 취 지와 난이도에 맞게 재구성한 프로그램이다. 각 단계에는 시공 간 잡기장(visuospatial sketchpad) 및 음운 고리(phonological loop), 임시 완충기(episodic buffer) 및 중앙집행기(central executive)와 연관된 12 개 유형의 과제들이 포함되었다. 1 단계에 서는 그림 순서(figures sequence) 및 숫자 목록, 빠진 그림 (missing one) 및 읽기/다시 말하기 과제가 시행되었다. 2단계 에서는 위치 순서(position sequence)와 단어 목록, 자기 순서 화(self-ordered task), 읽기/다시 말하기 과제가 적용되었다. 마 지막으로 3 단계는 복잡한 그림과 단어 산출, 이미지와 글, 읽 기/재인 과제로 구성되었다.

$\mathrm{ST}$ 집단의 중재는 크게 세 단계로 구성되었다. 첫 번째는 암 송 단계로, 제시된 문장을 읽은 후 들려주는 연관 및 비연관 단 어 목록을 회상하는 과제이다. 각 세트마다 1 개의 문장이 주어 지며, 이에 대해 2 8개까지 단어 목록이 제시된다. 단어는 55세 이상의 한국 성인이 자주 사용하는 어휘, 의미 전형성 및 산출 빈도 등을 고려하여 선정하였다(Kim et al., 2015). 연관 및 비 연관 단어 목록으로 구성된 세트는 각각 14 개씩 총 28 세트이 다. 두 번째는 '시각적 심상' 단계로서, 이전 단계에서 오반응을 보인 세트에 대해 시각적 이미지를 떠올리고 이에 부합하는 그 림카드를 선택한다. 그림카드는 단어의 의미를 간접적·추상적·
포괄적으로 드러내는 자극으로 구성되었다. 카드를 선택하고 나면 목표 단어 목록을 회상한다. 이 과정을 모두 완료하면 새 로운 자극으로 구성된 14 개 세트가 동일한 방식으로 추가된다. 세 번째 단계는 '이야기 말하기(storytelling)' 과제로 구성되며, 이전 단계에서 오반응을 보인 세트에 대해 짧은 이야기를 구성 한 후 목표 단어 목록을 회상한다. 이를 모두 완료하면 새로운 자극으로 구성된 14개 세트가 동일한 방식으로 추가된다.

CT 및 ST 중재의 세부 내용과 예시는 Table 3과 4에 각각 제 시하였다.

\section{연구 절차}

본 연구에 적용된 CT 및 ST 패러다임은 각각 세 단계에 걸 쳐 진행되었다. 즉 기초선 단계 1 회기, 중재 단계 10 회기, 전이 효과 단계 1회기로 구성되었다(Figure 1). 모든 단계는 총 8 주 동안 연속적으로 진행되었다. 기초선 및 전이 효과 단계는 중재 단계 전후 각 1 주씩, 중재 단계는 주 2 회 4주 및 주 1 회 2주씩 시행하였다.

\section{기초선 단계}

두 중재 패러다임을 적용하기 이전의 수행력을 파악하기 위 해 중재의 첫 번째 회기에 작업기억 및 언어 능력을 평가하였 다. 작업기억의 두 하위 영역에 해당하는 총 4 개 과제, 언어 능 력의 4 개 하위 영역에 대한 5 개 과제를 순서에 상관없이 무작 위로 실시하였다. 평가에 소요된 시간은 평균 20 30분이었다.

작업기억은 단어 폭과 숫자 폭에 해당하는 각각의 두 하위 과제를 합산하여 제시하였다.

읽기 이해에서 빈 칸이 포함된 하나의 문장과 이에 대한 질 문으로 구성된 자극판이 제시되면 피험자가 이를 읽은 후 4 개 의 단어 중 하나를 선택하도록 한다. 2 개 문항에 모두 정반응 시 2점, 1개 정반응 시 1점, 이외 반응은 0점을 부여하였다.

비유언어 과제는 속담, 직유, 관용구의 이해를 평가하는 3개 문항(예: 다음 중 '얼굴이 보름달 같다'에 해당하는 그림을 고르 세요)을 각각 청각적으로 제시한 후 3 개의 보기 중 하나를 선택

Table 2. Pre-post assessments

\begin{tabular}{llcl}
\hline \multicolumn{1}{c}{ Domain } & \multicolumn{1}{c}{ Subdomain } & Total score & \multicolumn{1}{c}{ Task } \\
\hline Working memory & Word span & $0-17$ & $\begin{array}{l}\text { Forward } \\
\text { Backward } \\
\end{array}$ \\
& Digit span & $0-17$ & $\begin{array}{l}\text { Forward } \\
\text { Backward } \\
\text { Language }\end{array}$ \\
& Reading comprehension & & Sentence comprehension \\
& Figurative language & 2 & Comprehension/expression \\
& Word fluency & 8 & Semantic word fluency ('fruit') \\
& & - & $\begin{array}{l}\text { Phonemic word fluency (' } \neg \text { ') } \\
\text { Story retelling }\end{array}$ \\
\hline
\end{tabular}


Table 3. Description of core training paradigm on the working memory intervention

\begin{tabular}{|c|c|c|c|}
\hline Component & Step & Task & Example \\
\hline \multirow{6}{*}{$\begin{array}{l}\text { Visuospatial sketchpad/ } \\
\text { phonological loop }\end{array}$} & 1 & Figures sequence & Remember the presented shapes and speak it in order \\
\hline & & Number list & Speak the list of numbers presented \\
\hline & 2 & Position sequence & Remember and speak the location of the presented picture \\
\hline & & Word list & Speak the list of words presented \\
\hline & 3 & Complex figures & Remember and draw the pictures within a limited time \\
\hline & & Word generation & Speak/write the words of specific categories \\
\hline \multirow{6}{*}{$\begin{array}{l}\text { Episodic buffer/ } \\
\text { central executive }\end{array}$} & 1 & Missing one & See the first picture and speak the missing one on the second picture \\
\hline & & Reading/retelling & Read a story and retell immediately \\
\hline & 2 & Self-ordered task & Point to a previously unselected picture of a set of cards that are out of sequence \\
\hline & & Reading/retelling & Read a story and retell again after 5 minutes \\
\hline & 3 & Images and text & See related pictures, read a part of a text, and complete the text \\
\hline & & Reading/recognition & Read a story and answer questions \\
\hline
\end{tabular}

Table 4. Description of strategy training paradigm on the working memory intervention

\begin{tabular}{|c|c|c|}
\hline \multirow{2}{*}{ Step } & \multicolumn{2}{|r|}{ Task } \\
\hline & Process & Example of stimulus \\
\hline \multirow[t]{6}{*}{ Rehearsal } & Reading a set of sentences & I like something beautiful \\
\hline & Listening to a list of related words & Rose-dress \\
\hline & Serially recalling related words & - \\
\hline & Reading a set of sentences & I like something beautiful \\
\hline & Listening to a list of unrelated words & Carrot-electric rice cooker \\
\hline & Serially recalling unrelated words & - \\
\hline \multirow[t]{5}{*}{ Visual imagery } & Reading a set of sentences & I got dressed up for the party \\
\hline & Listening to a list of related/unrelated words & Suit-hat-watch (related), desk-computer-pencil case (unrelated) \\
\hline & Creating an image for each word & Desk: square/classroom/book \\
\hline & Selecting a picture card for an image & - \\
\hline & Serially recalling words & Suit-hat-watch (related), desk-computer-pencil case (unrelated) \\
\hline \multirow[t]{4}{*}{ Storytelling } & Reading a set of sentences & I did grocery shopping \\
\hline & Listening to a list of related/unrelated words & $\begin{array}{l}\text { Bus-coat-potato-wallet (related), } \\
\text { medicine-camping car-monkey-bed (unrelated) }\end{array}$ \\
\hline & Making up a short story of words & $\begin{array}{l}\text { I put on my coat and went to the bus station. I wanted to buy fresh } \\
\text { potatoes at the grocery store. But I did not find my wallet }\end{array}$ \\
\hline & Serially recalling words & $\begin{array}{l}\text { Bus-coat-potato-wallet (related), } \\
\text { medicine-camping car-monkey-bed (unrelated) }\end{array}$ \\
\hline
\end{tabular}

하도록 한다. 정반응은 2점, 5 10초 내 정반응은 1점, 10초 후 정반응 및 오반응은 0 점을 부여하였다. 비유언어의 표현 영역은 문장(예: 어제는 오랜만에 대중목욕탕에 갔는데 하필이면 '정기 휴일'이라고 한다)을 듣고 해당되는 속담을 말하도록 하며, 정반 응은 2점, 정확한 내용은 아니나 수용 가능한 정보 및 적절한 표현인 경우 1 점, 이외 반응에는 0점을 부여하였다.

단어유창성은 의미적 및 음운적 단어유창성 과제의 각 범주 에 해당하는 단어를 제한된 시간(1분) 내에 최대한 많이 말하 도록 한다. 채점 시에는 두 하위 과제에서 산출한 단어의 개수 를 합산하여 총점으로 산정하였다.

담화 산출 과제는 먼저 특정 주제(예: ‘충치')에 대한 구를 들
려준 후 다시 말하도록 하는 ‘이야기 다시 말하기' 과제이다. 통 일성(coherence), 응집성(cohesion), 명제(proposition), 심 (pauses)을 포함한 4개 지표에 대해 각 기준에 부합하는 정도 에 따라 점수를 산정한 후 총점을 제시하였다. 예를 들어 통일 성은 정보의 구체성, 주제와의 일치성 등에 따라 4점 척도 $(3,2$, $1,0)$ 로, 응집성은 대명사, 지시관형사, 올바른 반복 등 결속장치 의 수에 따라 3 점 척도 $(2,1,0)$ 로 채점하였다. 명제 지표는 관련 된 명제의 수에 따라 3점 척도 $(2,1,0)$ 를, 그리고 심은 발화 개 시 및 중간 시점에 나타난 쉼의 길이(초)에 따라 2점 척도 $(1,0)$ 를 적용하였다. 통일성의 경우 각 발화마다 점수를 부여한 후 그 평균값을 최종 점수로 산정하였다. 


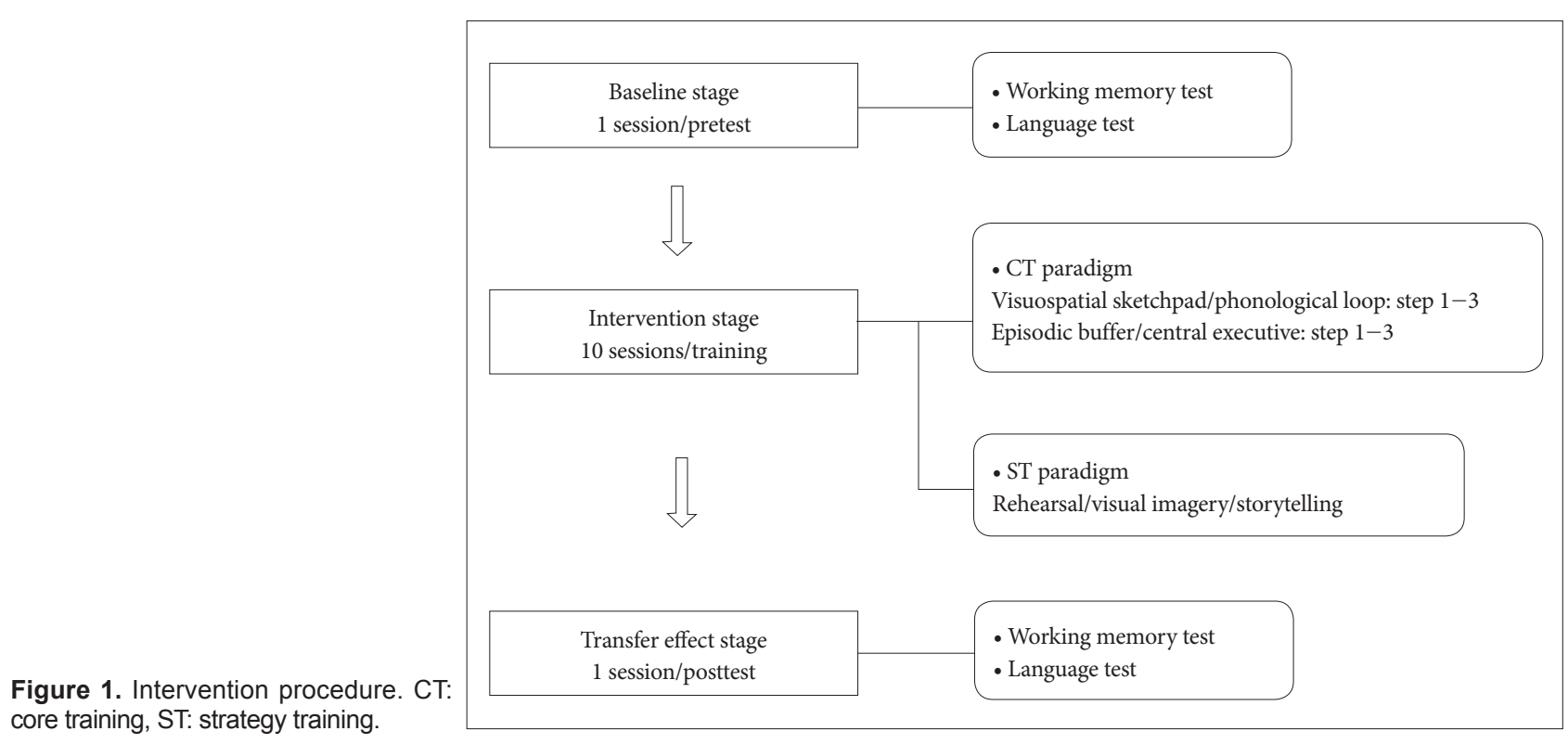

\section{중재 단계}

중재 단계에서는 CT 및 ST 집단을 대상으로 각 중재 패러다 임을 적용하였다(Table 3, 4). 중재는 회기당 30 40분씩 총 10 회기를 진행하였다.

\section{$\mathrm{CT}$ 패러다임}

$\mathrm{CT}$ 중재에서는 작업기억의 4 개 기제별 하위 과제들로 구성 된 3단계의 패러다임을 적용하였다.

1 단계의 시공간 잡기장 및 음운 고리 영역은 제시된 도형(예: 삼각형, 사각형)을 기억한 후 순서대로 말하는 '그림 순서' 과제, 그리고 제시된 숫자 목록(예: 1-3-6)을 따라 말하는 '숫자 목 록' 과제로 구성되었다. 도형 및 목록에 포함된 숫자는 2 6개가 제시되었다. 임시 완충기 및 중앙집행기 영역에는 첫 번째 카드 (예: 개-숟가락-양말-자전거)에 있던 그림들 중 두 번째 카드 (예: 개-숟가락-양말)에서 빠진 1개의 그림을 말하는 "빠진 그 림' 과제, 이야기(예: 동물원 이야기)를 읽고 곧바로 다시 말하 는 '읽기/다시 말하기' 과제가 포함되었다. 목록에 포함된 단어 의 개수는 2 6개, 서로 다른 이야기의 유형은 총 10 개가 제시되 었다. 1단계의 모든 과제에 대해 자발적인 수행력이 $70 \%$ 이상이 거나 단서를 제공한 후의 수행력이 $80 \%$ 이상일 경우 2 단계를 진행하였다. 단서로는 시각 및 청각 자극의 반복, 목표 단어에 대한 의미 및 음소 단서, 이야기와 관련된 추가적인 내용(예: 원 숭이 우리 앞에 다른 동물이 있었어요) 등이 제공되었다.

2 단계의 시공간 잡기장 및 음운 고리 영역에서는 제시된 그 림(예: 다른 모양의 블록 그림)의 위치를 기억하여 말하는 '위치 순서' 과제, 제시된 단어 목록(예: 연필-무-선풍기)을 따라 말 하는 '단어 목록' 과제가 시행되었다. 그림 및 목록에 포함된 단
어는 2 6개로 구성되었다. 임시 완충기 및 중앙집행기 영역에 는 순서가 바뀐 그림들로 구성된 카드 세트(예: 공-꽃-볼펜) 중 이전에 선택하지 않은 그림을 하나씩 가리키는 '자기 순서화 과제(self-ordered task)', 이야기(예: 쇼핑 이야기)를 읽고 5분 후에 다시 말하는 '읽기/다시 말하기' 과제가 포함되었다. 이야 기의 지문은 1 단계에 비해 평균 2 3개의 문장이 더 추가되었 다. 자기 순서화 과제의 카드에는 3 6개의 그림들이 제시되었 고, 서로 다른 이야기의 유형은 총 10 개가 제시되었다. 2 단계의 모든 과제에 대해 자발적인 수행력이 $70 \%$ 이상이거나 단서를 제공한 후의 수행력이 $80 \%$ 이상일 경우 3단계를 진행하였다. 단서로는 시각 및 청각 자극의 반복, 선택한 그림을 그리거나 단 어로 쓰기(자기 순서화 과제), 이야기와 관련된 추가적인 내용 (예: 과일 다음에 산 채소가 있어요) 등을 제공하였다.

3 단계의 시공간 잡기장 및 음운 고리 영역은 제한된 시간 내 에 그림(예: 다른 모양의 선과 면으로 구성된 기하학적 그림)을 기억하여 그리는 '복잡한 그림' 과제, 특정 범주(예: 가구)에 해 당하는 단어를 말하거나 쓰는 '단어 산출' 과제로 구성하였다. 그림은 5 개의 난이도에 따라 제시하였다. 범주는 55 세 이상의 한 국 성인이 자주 사용하는 어휘를 참고하였고(Kim et al., 2015), 의미 전형성 및 산출 빈도를 고려하여 총 10 개의 유형을 최종적 으로 선정하였다. 임시 완충기 및 중앙집행기 영역으로는 글과 관련된 그림(예: 과일 가게)을 보고 글의 일부를 읽은 다음 내 용을 완성하여 말하는 '이미지와 글' 과제, 이야기(예: 단풍 이 야기)를 읽고 관련된 질문에 대답하는 '읽기/재인' 과제를 시행 하였다. 서로 다른 주제의 글과 이야기는 각각 10 개씩 제시되었 고, '읽기/재인' 과제의 질문은 이야기당 3 5개씩 시행되었다. 3 단계는 과제에 대한 수행력과 상관없이 종료 시점까지 진행되 
었다. 단서로는 시각 및 청각 자극의 반복, 의미 단서(단어 산출 과제), 이야기와 관련된 추가적인 내용(예: 강원도에 있는 산에 갔어요) 등을 제공하였다.

\section{ST 패러다임}

$\mathrm{ST}$ 패러다임 중재는 크게 세 단계로 구성되었다.

암송 단계는 문장 읽기, 연관 단어 목록 듣기, 순서대로 단어 회상하기, 문장 읽기, 비연관 단어 목록 듣기, 순서대로 단어 회 상하기 순으로 진행하였다. 예를 들어 '나는 아름다운 것을 좋 아해요라는 문장을 읽은 후, 청각적으로 제시되는 연관 단어 목록(예: 장미-드레스)을 기억하고 순서대로 회상하여 말한다. 동일한 문장이 한 번 더 제시되고 비연관 단어 목록(예: 당근전기밥솥)을 들으면 이를 순서대로 회상하여 말한다. 오반응 시 에는 문장과 단어 목록으로 구성된 각 세트를 2 회 더 반복해 시행하고, 마지막 시행까지 $100 \%$ 의 수행력을 보이지 않더라도 다음 세트를 진행하였다.

시각적 심상 단계는 이전 단계에서 오반응을 보인 세트부터 시작해 수행력에 따라 세트를 추가하였다. 암송 단계와 마찬가 지로, 문장 읽기와 연관 단어 목록 듣기를 진행한 후 각 단어에 대한 시각적 이미지를 마음속으로 떠올리도록 하였다. 이때 단 어 목록의 양에 따라 제한 시간을 다르게 제공했는데, 1 개 단 어당 10 초씩 할당하였다. 그러고 나서 자신이 떠올린 이미지에 해당하는 그림카드를 고르도록 하였다. 그림카드는 단어 목록 의 2 배수가 제공되었다. 예컨대 '책상'에 대해서는 '사각형-교 실-책' 등의 이미지를 떠올릴 수 있고, 여러 그림카드 중 이에 해당하는 것을 선택하도록 한다. 수행에 어려움이 있을 경우 의 미적 단서(예: 모양이 어떻지요?)를 제공하였다. 마지막으로 목 표 단어 목록을 회상하여 말하도록 요구하였다. 오반응 시에는 해당 세트 전체를 1회 더 반복해 시행하고, 마지막 시행까지 $100 \%$ 의 수행력을 보이지 않더라도 다음 세트를 진행하였다.

이야기 말하기 단계는 이전 단계에서 오반응을 보인 세트부 터 시작해 수행력에 맞춰 세트를 추가하였다. 이전 두 단계처럼 문장과 단어 목록을 제시한 후 해당 단어들을 활용해 짧은 이 야기를 구성하도록 하였다. 예를 들어 '버스-코트-감자-지갑' 이라는 단어 목록에 대해 '나는 코트를 입고 버스 정류장으로 갔다. 식료품점에서 감자를 사려고 했으나 지갑을 찾을 수 없 었다와 같은 이야기를 구성한다. 이후에는 목표 단어 목록을 회상하여 말하도록 요구하였고, 오반응 시에는 해당 세트 전체 를 1 회 더 반복적으로 시행하였다. 수행하지 못하거나 부분적 으로 시행할 경우 의미적 단서(예: 코트를 입은 다음에는 어디 로 갔지요?)를 제공하였다.

\section{전이 효과 단계}

두 집단에 대한 작업기억 중재를 완료한 직후 1 회기 동안 사 후 평가를 실시하였다. 기초선 단계와 마찬가지로 작업기억 및 언어 능력에 대해 평가하였다. 과제의 순서에 상관없이 무작위 로 진행하였으며, 평가 시간은 20 30분 정도 소요되었다. 채점 방식은 기초선 단계와 동일하게 적용하였다.

\section{통계 분석}

본 연구는 사전-사후 비교 설계(pretest-posttest design)에 기초하였고, 통계분석 프로그램으로써 SPSS 21.0 version (IBM Corp., Armonk, NY, USA)이 활용되었다. 연령과 성별, 교육 연수, K-MMSE 점수상 집단 간의 차이가 있는지를 확인 하기 위해 독립표본 $t$-검정(independent samples $t$-test)을 사 용하였고, 기술통계 결과에 근거해 과제별 수행력을 제시하였 다. 두 집단을 대상으로 실시한 중재 전후의 수행력 차이를 검 증하기 위해 비모수적 통계방법인 윌콕슨 결합-조 기호-순위 검정(Wilcoxon matched-pairs signed-ranks test)을 활용하였 다. 사전-사후 평가에서 두 집단 간 수행력의 차이는 맨 휘트니 유 검정(Mann-Whitney U test)을 통해 비교하였다.

\section{RESULTS}

\section{중재 전후의 수행력 비교}

두 집단에서 중재 전후의 수행력에 차이가 있는지를 비교한 결과는 Table 5 와 6 에 각각 제시하였다.

$\mathrm{CT}$ 집단의 언어 측면에서 비유언어 $(\mathrm{Z}=-3.017, p<0.01)$, 단어유창성 $(\mathrm{Z}=-2.694, p<0.01)$, 담화 산출 $(\mathrm{Z}=-2.937, p<$ 0.01) 능력이 중재 전에 비해 유의미하게 향상되었다. 반면에 읽 기 이해는 중재로 인한 효과가 나타나지 않았다 $(\mathrm{Z}=-1.732, p=$ 0.083).

$\mathrm{ST}$ 집단의 경우 비유언어 $(\mathrm{Z}=-2.449, p<0.05)$ 와 담화 산출 $(\mathrm{Z}=-2.003, p<0.05)$ 에서는 중재 전후의 차이가 유의미한 반 면, 읽기 이해 $(\mathrm{Z}=-0.577, p=0.564)$ 와 단어유창성 $(\mathrm{Z}=-1.926$, $p=0.541)$ 은 중재 효과가 없었다.

작업기억 측면에서는 $\mathrm{CT}$ 집단이 단어 폭 $(\mathrm{Z}=-2.889, p<$ $0.01)$ 과 숫자 폭 $(\mathrm{Z}=-2.724, p<0.01)$ 에서 중재 전후의 차이가 유의미한 것으로 나타났다. ST 집단도 단어 폭 $(\mathrm{Z}=-2.739, p<$ $0.01)$ 과 숫자 폭 $(\mathrm{Z}=-2.714, p<0.01)$ 과제 모두에서 중재 효 과가 유의미하였다.

\section{전이 효과에 대한 집단 간 비교}

사전-사후의 차이에 있어 두 집단을 비교함으로써 중재 패 러다임이 전이 효과에 미치는 영향을 알아보았다(Table 7). 
Table 5. Cognitive-linguistic abilities of pre and post intervention in core training group $(n=12)$

\begin{tabular}{lcccc}
\hline \multicolumn{1}{c}{ Domain } & Pre scores & Post scores & Z & $p$ \\
\hline Working memory & & & & $<0.01$ \\
$\quad$ Word span & $3.67( \pm 2.35)$ & $5.00( \pm 2.56)$ & -2.889 & $<0.01$ \\
$\quad$ Digit span & $3.08( \pm 2.27)$ & $4.25( \pm 2.42)$ & -2.724 & \\
Language & & & & \\
$\quad$ Reading comprehension & $1.42( \pm 0.67)$ & $1.67( \pm 0.49)$ & -1.732 & $<0.01$ \\
$\quad$ Figurative language & $4.50( \pm 1.88)$ & $5.83( \pm 1.99)$ & -3.017 & $<0.01$ \\
$\quad$ Word fluency & $7.50( \pm 3.69)$ & $8.63( \pm 3.96)$ & -2.694 & $<0.01$ \\
$\quad$ Discourse production & $2.53( \pm 1.15)$ & $3.33( \pm 0.70)$ & -2.937 & \\
\hline
\end{tabular}

Table 6. Cognitive-linguistic abilities of pre and post intervention in strategy training group $(n=12)$

\begin{tabular}{lcccc}
\hline \multicolumn{1}{c}{ Domain } & Pre scores & Post scores & Z & $p$ \\
\hline Working memory & & & & $<0.01$ \\
$\quad$ Word span & $3.83( \pm 2.76)$ & $5.00( \pm 3.10)$ & -2.739 & $<0.01$ \\
$\quad$ Digit span & $3.58( \pm 2.97)$ & $4.83( \pm 3.24)$ & -2.714 & \\
Language & & & & \\
$\quad$ Reading comprehension & $1.42( \pm 0.67)$ & $1.50( \pm 0.67)$ & -0.577 & $<0.05$ \\
$\quad$ Figurative language & $4.33( \pm 1.78)$ & $4.83( \pm 1.80)$ & -2.449 & 0.541 \\
$\quad$ Word fluency & $6.54( \pm 3.89)$ & $7.54( \pm 3.68)$ & -1.926 & $<0.05$ \\
$\quad$ Discourse production & $2.69( \pm 0.94)$ & $2.90( \pm 0.79)$ & -2.003 & \\
\hline
\end{tabular}

Table 7. Comparison of transfer effects between two groups

\begin{tabular}{|c|c|c|c|c|}
\hline \multirow{2}{*}{ Domain } & \multicolumn{2}{|c|}{ Pre-post differences } & \multirow{2}{*}{$\mathrm{U}$} & \multirow{2}{*}{$p$} \\
\hline & CT group & ST group & & \\
\hline \multicolumn{5}{|l|}{ Working memory } \\
\hline Word span & $1.33( \pm 0.78)$ & $1.17( \pm 0.83)$ & 69.500 & 0.880 \\
\hline Digit span & $1.17( \pm 0.94)$ & $1.25( \pm 0.97)$ & 67.000 & 0.759 \\
\hline \multicolumn{5}{|l|}{ Language } \\
\hline Reading comprehension & $0.25( \pm 0.45)$ & $0.08( \pm 0.51)$ & 61.500 & 0.422 \\
\hline Figurative language & $1.33( \pm 0.65)$ & $0.50( \pm 0.52)$ & 27.000 & $<0.01$ \\
\hline Word fluency & $1.13( \pm 0.83)$ & $1.00( \pm 1.49)$ & 71.000 & 0.953 \\
\hline Discourse production & $0.79( \pm 0.60)$ & $0.20( \pm 0.30)$ & 23.000 & $<0.01$ \\
\hline
\end{tabular}

CT: core training, ST: strategy training

언어 능력에 대한 전이 효과는 과제에 따라 다르게 나타났다. 비유언어 $(\mathrm{U}=27.000, p<0.01)$ 와 담화 산출 $(\mathrm{U}=23.000, p<$ 0.01)은 두 집단의 사전-사후 차이가 유의미하였다. 이는 중재 패러다임의 유형이 중재 효과에 관여했음을 의미한다. 이와 대 조적으로 읽기 이해 $(\mathrm{U}=61.500, p=0.422)$ 와 단어유창성 $(\mathrm{U}=$ $71.000, p=0.953)$ 은 집단 간의 사전-사후 차이가 유의미하지 않았다. 즉 중재 패러다임의 유형이 중재 효과에 영향을 주지 않았다.

작업기억에 대한 전이 효과를 살펴보면 단어 폭 $(\mathrm{U}=69.500$, $p=0.880)$ 과 숫자 폭 $(\mathrm{U}=67.000, p=0.759)$ 에서 두 집단 간의 사전-사후 차이가 유의미하지 않았다. 즉 작업기억 중재 패러다 임의 유형이 작업기억에 대한 전이 효과에 영향을 미치지 않았다.

\section{DISCUSSIONS}

본 연구에서는 작업기억 중재 패러다임의 유형이 $\mathrm{AD}$ 환자의 언어 능력에 대한 전이 효과에 어떠한 영향을 미치는지 비교하 였다. 이를 위해 두 $\mathrm{AD}$ 집단에게 $\mathrm{CT}$ 및 ST 패러다임이 적용된 작업기억 중재를 각각 시행한 후 중재 전후의 차이를 집단별로 살펴보았다. 또한 이러한 차이가 두 집단 간에 유의한지를 비교 함으로써 중재 패러다임의 유형이 언어 능력에 대한 전이 효과 에 미치는 영향을 분석하였다.

작업기억과 다른 인지-언어 능력의 상관성이 부각되면서 작 업기억 중재의 효과성에 대한 논의가 활발해지고 있다(Kane et al., 2004). 억제나 처리 속도 등 작업기억과 관련된 기제, 그리고 
유동성 지능이나 언어 이해 등 작업기억을 기반으로 한 인지 처 리에 있어 작업기억 중재의 전이 효과가 입증된 바 있다(Borella et al., 2010; Carretti et al., 2013b). 특히 기억상실형(amnestic) mild cognitive impairment 환자에게 구어 작업기억 중재를 실 시하면 시지각 작업기억, 유동성 지능, 장기기억 측면에서 효과 적이라는 보고가 있다(Carretti et al., 2013a).

작업기억 중재가 언어 능력에 미치는 효과는 주로 이해 측면 에 국한되었다. 예를 들어 작업기억 중재를 받은 노인의 언어 이해가 크게 향상되었고, 6개월 후에도 이에 대한 유지 효과가 나타났다(Carretti et al., 2013b). 질문에 대답하기, 문장-그림 짝 맞추기 등 정보를 회상하거나 활용하는 과제는 기억에 보유 한 정보를 처리하는 데 효과적인데(Peach \& Shapiro, 2012), 중 재를 통해 정상군과 $\mathrm{AD}$ 환자의 음운 인식과 구어 회상의 정확 도, 계산 및 언어 이해가 향상된다.

언어 표현 측면의 중재 효과를 살펴보면 컴퓨터 프로그램 기 반의 작업기억 중재가 문장 기억과 단어유창성을 향상시킨다 는 보고들이 있다(Lee \& Kim, 2019). 문장을 산출하기 위한 계 획은 구어 작업기억과 크게 연관되는데, 음운을 계획하는 데 할 당되는 자원이 중복적이므로 이에 대한 중재를 통해 음운 수준 에서 계획의 효율성을 높일 수 있다. 시 기반 자극(poetry-based stimulation)과 같은 언어 기반 과제를 병행하여 작업기억 중재 를 시행하면 단어유창성, 담화 산출 능력이 향상된다는 주장도 있다(Zimmermann et al., 2014).

본 연구에서는 비유언어와 읽기 과제를 통해 언어 이해 능력 을 살펴보았는데, CT와 ST 집단에서 공통적으로 비유언어 영 역의 중재 효과가 유의하게 나타났다. 비유언어를 처리하기 위 해서는 개념적 단위를 통합하는 인지-언어 능력이 요구된다 (Benitez-Burraco, 2017). 다영역적 사고 과정은 문장 구조의 핵심을 이루며, 비유언어를 처리하고 사용하는 능력을 향상시 킨다(Benitez-Burraco, 2017). 작업기억 기제는 이 과정에서 가 장 핵심적인 역할을 한다. 실제로 비유언어 이해, 기억력, 집행 기능은 노화나 신경학적 질환으로 인한 인지-언어적 변화의 주 요 예측변인이라는 연구 결과도 있다(Lee, 2017).

본 연구에서 읽기 이해는 CT 및 ST 집단 모두에서 중재 효 과가 나타나지 않았다. 이에 대한 연구 결과는 다양한데, CT의 전이 효과가 매우 크게 나타나는 과제 중 하나로 읽기 이해를 꼽는 견해가 있다(Morrison \& Chein, 2011). 반면에 암송, 청킹, 시각적 심상, 이야기 말하기 등 다양한 ST 전략을 활용하면 지 시 따르기 능력, 계산 능력 등은 향상되나 읽기 이해에는 영향을 미치지 않는다는 보고도 있다(St Clair-Thompson et al., 2010).

비유언어와 단어유창성, 담화 산출 과제로 살펴본 언어 표현 중에는 담화 산출의 중재 효과가 두 집단 모두에서 유의미하였 다. 단어유창성은 $\mathrm{CT}$ 집단에서 유의하게 향상된 반면, ST 집단
에서는 중재 효과가 없었다. 담화 산출은 언어의 의미 및 구문, 화용 능력이 통합적으로 관련되므로 $\mathrm{AD}$ 의 인지-언어적 수행력 을 민감하게 반영한다(Kim \& Lee, 2019). 특히 담화 과제에서 요 구되는 음운적 지식, 의미적 효율성, 통사적 활용, 거시 구조의 정교화, 응집성 및 통일성, 정보 전달의 적절성 등은 주의력, 집행 기능, 작업기억과 같은 인지 기제와 직결된다(Kim \& Lee, 2019). 특히 본 연구에서 적용한 CT 패러다임은 Baddeley(2009)의 작 업기억 모델에 근거하여 시공간 잡기장, 음운 고리, 임시 완충 기, 중앙집행기와 관련된 하위 과제들로 구성되었다. 이는 주의 력 통제, 다른 하위 체계로부터의 정보와 구어 정보의 조작 및 저장, 분리 주의력, 시지각 및 운동감각과 이미지 부호의 해독, 작업기억 하위 체계와 다른 인지 체계와의 상호작용 등을 복합 적으로 다룬다. 본 연구에서 나타난 $\mathrm{CT}$ 패러다임의 중재 효과 는 담화와 같은 고차원적 언어 기능이 복합적인 작업기억 중재 및 자극을 통해 극대화된다는 데 근거한다(Zimmermann et al., 2014).

ST는 부호화, 유지, 작업기억으로부터의 인출에 효과적인 패 러다임으로 알려져 있다(Morrison \& Chein, 2011). 이는 정보 의 보유를 요하는 과제의 수행력을 증진시키는 데 효과적인데, 조음 암송 과제나 정교한 부호화 전략 등이 대표적이다(Carretti et al., 2007). 본 연구에서도 암송, 시각적 심상, 이야기 말하기 로 구성된 ST 패러다임을 적용했는데, 중재 시마다 각 과제를 소개한 후 전략에 대한 흥미와 동기를 북돋는 연습 회기를 반 복적으로 제공하였다. 특히 정교한 부호화 전략으로써 항목들 을 묶어 청크화하고 항목과 관련된 이야기를 고안하거나 심상 을 활용하는 기법을 적용함으로써 중재 효과를 극대화하고자 하였다(Carretti et al., 2007; St Clair-Thompson et al., 2010). 이러한 과정이 음운적 지식, 어휘-의미, 거시 구조의 정교화, 응집성 및 통일성에 긍정적으로 기여함으로써 담화 산출 능력 을 향상시킨 것으로 보인다.

언어 능력에 대한 원전이 효과는 두 집단 모두에서 나타난 작업기억의 증진에 기초한다. 즉 $\mathrm{CT}$ 와 $\mathrm{ST}$ 패러다임 중재를 통 해 단어 폭과 숫자 폭 과제의 수행력이 증진되면서 언어 능력에 대한 전이 효과가 나타났다. 이는 용량의 확장과 효율성의 강화 라는 차원에서 설명된다. 작업기억 용량이 확장되면 중재 이전 에 비해 더 많은 항목을 동시에 보유할 수 있는데, 이는 중재를 통해 작업기억 용량의 제한에 영향을 주는 뇌 영역이 변화했음 을 의미한다. 작업기억의 효율성은 작업기억과 동일한 구조적 자원에 의존하는 인지 능력이 향상되는 데 관여하며, 이는 신 경학적으로 뉴런의 중복(neuronal overlap)을 통해 확인된다 (Dahlin et al., 2008).

작업기억 용량이 확장되면서 훈련 과제의 변화가 공유되기 때문에 동시 발생적으로 비훈련 과제의 수행력도 향상된다 
(Klingberg, 2012). 작업기억 용량과 다른 인지-언어 능력 간의 상관성이 클수록 전이 효과가 크다. 작업기억 용량이 다양한 인 지-언어 능력과 연관되면 과제의 유형이나 구조에 상관없이 작 업기억 용량의 확장에 기반한 전이 효과가 여러 영역에서 매우 광범위하고 명확하게 나타난다(McArdle \& Prindle, 2008). 본 연구에서 두 집단은 모두 작업기억에 대한 근전이 효과를 보였 고, 이를 기반으로 하여 언어 능력에 대한 원전이 효과가 중재 패러다임에 따라 다르게 나타났다. CT는 다양한 유형의 과제를 포괄하기 때문에 대상자의 동기 의식을 높게 유지할 뿐 아니라 목표화된 인지 처리가 다른 맥락에서 연습될 때 실질적인 전이 를 촉진한다. 특히 고차원적이고 복합적인 처리 과정에 기반한 언어 능력으로의 전이는 몇몇 선행연구를 통해 입증된 바 있다 (Lee \& Kim, 2019; Peach \& Shapiro, 2012).

$\mathrm{CT}$ 와 대조적으로 ST와 같은 단일 패러다임은 업데이트나 저장, 처리와 같은 작업기억의 특정 양상이나 기능에 적응하도 록 유도한다(Chein \& Morrison, 2010). ST의 근전이 효과는 여 러 연구에서 입증된 반면, 원전이 효과에 대한 견해는 상대적 으로 다양하다(Thompson et al., 2013). 본 연구에서 CT 패러 다임의 원전이 효과는 ST에 비해 더 다양한 언어 영역에서 나 타났으나, 여기에는 몇 가지 변수가 존재한다. 단기기억과 작업 기억은 유사한 기제이기 때문에 훈련한 요소가 명확히 작업기 억 용량에 영향을 미쳤는지 여부가 모호하다(Shipstead et al., 2012). 또한 단기기억이 일차적 기억을 반영하는 반면 작업기억 과제, 특히 폭 과제는 장기기억과 같은 광범위한 부수적 기억도 관여된다(Unsworth \& Engle, 2007).

본 연구에서 두 집단의 전이 효과를 비교한 결과는 중재 패 러다임의 유형이 인지-언어 능력에 대한 효과에 미치는 영향을 정량화했다는 점에서 의미가 있다. 비유언어와 담화 산출 능력 은 CT 패러다임의 중재 효과가 더 크게 나타난 반면, 읽기 이 해와 단어유창성, 작업기억은 중재 패러다임의 영향을 받지 않 았다. CT는 주로 요구 수준이 높은 작업기억 과제로 구성되는 데, 영역 특수적 전략의 사용을 제한하고 자동화를 최소화하 며 다양한 양식에 걸친 과제 및 자극을 활용하는 데 중점을 둔 다(Morrison \& Chein, 2011). 본 연구에서도 시공간 잡기장 및 음운 고리, 임시 완충기, 중앙집행기 등 작업기제의 하위 체계 와 연관된 12 개 유형의 과제로 구성된 CT 패러다임을 적용하 였다. 이 같은 구조로 인해 내적 및 외적 방해에 직면할 때 유 지를 요구하고 빠른 부호화 및 인출이 강화될 뿐 아니라 대상 자의 다양한 수준에 따른 조정이 가능하다.

$\mathrm{CT}$ 패러다임은 중재 과정에서 인지 부담이 크고 높은 강도 의 인지 참여를 요하며, 순차적 처리와 빈번한 기억 업데이트가 포함된다(Chein \& Morrison, 2010). 이로 인해 비순차적, 비적 응적, 단일 양식적 훈련 패러다임보다 전이 효과가 크다고 전제
된다(Olson \& Jiang, 2004). 예컨대 CT를 활용한 중재 이후에 업데이트, 작업기억 용량 등 작업기억의 특정 구성 요소를 향 상시키는 근전이 효과뿐 아니라 훈련되지 않은 인지-언어 영역 에 대한 원전이 효과가 나타났다(Dahlin et al., 2008). 또한 작 업기억 용량에 의존하는 다양한 범주의 다른 인지-언어 과제 의 수행력이 향상되며, 특히 인지 통제, 유동성 지능, 읽기 이해 와의 상관성이 크기 때문에 일상생활의 기능에도 긍정적으로 작용한다(Morrison \& Chein, 2011). 따라서 CT 패러다임의 이 같은 속성이 비유언어, 담화 산출과 같은 복잡하고 고차원적인 언어 능력의 중재 효과에 기여한 것으로 보인다. 즉 작업기억 체계의 다양한 구성 요소와 이들 간의 조합이 중재 효과를 극 대화시킨다는 CT 패러다임의 이점이 본 연구 결과에도 반영되 었음을 시사한다.

물론 CT의 효과성에 대한 이견도 존재한다. 다양한 과제와 자극, 처리로 구성된 CT의 다차원적 체계는 중재 효과의 어느 요소를 향상시켰는지 판단하기 어렵게 함으로써 효과를 보인 작업기억의 기제를 구분하는 데 혼선을 초래한다. 또한 과제의 복잡성에 따라 중재 효과가 달라진다는 점도 변수 중 하나이다 (Dahlin et al., 2008). 본 연구에서는 ST에 비해 상대적으로 $\mathrm{CT}$ 의 원전이 효과가 두드러졌으나, 이의 유지 효과에 대해서는 예측하기가 어렵다. 실제로 업데이트에 중점을 둔 $\mathrm{CT}$ 의 근전이 효과가 청장년층은 18 개월간 지속되었으나, 노인의 경우 3 개월 간 유지된 후 12 개월 시점에서 효과가 나타나지 않았다(Li et al., 2008).

한편 본 연구에서 중재 패러다임의 유형은 근전이 효과에 영 향을 미치지 않았다. 즉 중재로 인해 작업기억의 수행력이 향상 됨으로써 두 집단 모두에서 근전이 효과가 나타났지만, 중재 패 러다임의 유형에 따른 차이는 없었다. CT뿐 아니라 ST 패러다 임의 경우에도 근전이 효과를 입증한 연구들이 많다. 암송 훈 련은 효과적인 전략으로의 전환을 유도함으로써 작업기억 기 제를 뒷받침하는 내적 암송 기제의 효율성이나 질을 증진시키 며(Morrison \& Chein, 2011), 이야기 말하기나 심상의 활용 등 이 작업기억을 향상시킨다고 알려져 있다(Carretti et al., 2007). 본 연구와 동일한 맥락으로 노화나 신경학적 질환으로 인해 작 업기억이 저하된 경우에도 ST의 근전이 효과가 나타난다는 보 고도 있다(Carretti et al., 2013b).

그러나 여전히 ST 패러다임의 근전이 효과에 대한 이견이 많 고, 작업기억의 수행력을 직접적으로 증진하는 전략을 보완해 야 한다는 주장도 있다(Carretti et al., 2007). 즉 특정 기억 전 략에 의존한다는 특성 때문에 본 연구 결과와 마찬가지로 훈련 과제 중심의 근전이 효과는 나타나지만 비교적 상관성이 먼 언 어적 맥락으로 일반화되기는 어렵다.

요컨대 본 연구에서는 작업기억의 두 중재 패러다임이 $\mathrm{AD}$ 의 
언어 능력에 대한 전이 효과에 어떠한 영향을 주는지 살펴보았 다. 이를 통해 각 패러다임별로 중재 효과를 보이는 언어 과제 를 제시하였고, 유형에 따라 전이 효과가 더 크게 나타나는 영 역을 파악할 수 있었다. 본 연구의 임상적 의의는 다음과 같다. 첫째, 인지-의사소통의 핵심 영역으로서 작업기억이 갖는 중요 성을 증거 기반적으로 입증하였다. 둘째, $\mathrm{AD}$ 환자를 대상으로 한 작업기억 중재의 원전이 효과 연구가 미미한 국내 현실을 감 안할 때 인지-언어 중재의 방향성과 근거를 제시했다는 데 의 의가 있다. 셋째, 중재 효과에 대한 영향 요소를 명확히 파악할 수 없는 CT 패러다임의 단점을 고려하여 작업기억의 4개 기제 별로 하위 과제를 구성하고 이를 단계적으로 진행하였다. 즉 과 제와 자극, 처리 양식을 각 기제 및 단계에 따라 분리함으로써 중재 효과와 직결되도록 구조화하였다. 이는 CT 패러다임을 적 용할 때 각 영향 요소에 따라 중재를 계획하고 진전을 평가하 는 데 유용하게 활용될 것이다. 넷째, CT 패러다임이 비유언어, 담화 산출 등 고차원적 언어 능력의 중재 효과에 기여함을 입 증함으로써 작업기억 체계의 다양한 구성 요소와 조합이 중재 효과를 극대화한다는 점을 확인할 수 있었다. 다섯째, 작업기억 중재 후 원전이 효과를 갖는 언어 과제를 제시함으로써 $\mathrm{AD}$ 환 자에 대한 언어 재활 시 임상적 활용도와 효율성을 높이는 데 크게 기여할 것이다.

그럼에도 불구하고 본 연구는 다음과 같은 한계점을 지닌다. 첫째, 상대적으로 효과성이 크게 나타난 CT 패러다임의 경우 이에 영향을 미친 요소를 명확히 파악할 수 없다는 단점이 있 다. 본 연구에서는 이를 최소화하기 위해 작업기억의 하위 기제 및 단계별로 구조화된 $\mathrm{CT}$ 패러다임을 적용하였으나, 중재 효 과에 대한 직접적인 영향 요인은 여전히 모호하다. 이는 향후 연구를 통해 중재 효과의 주요 변인으로서 고려되어야 할 것이 다. 둘째, 본 연구의 CT 패러다임은 작업기억의 하위 체계들을 중심으로 구성되었다. 훈련 및 전이 과제 모두에서 요구되는 처 리 과정이 중복되면서 전이 효과가 두드러진다는 가정에 근거 할 때 하나의 영역보다는 다수의 인지-언어 능력에 목표를 둔 패러다임도 고려할 필요가 있다. 즉 작업기억, 집행 기능, 문제 해결, 언어 등 여러 영역에 기반한 이질적인 과제로 구성하면 중재 효과에 미치는 영향이 달라질 수 있다. 셋째, 유지 효과에 대해서도 고려할 필요가 있다. 본 연구는 중재가 끝난 시점에서 사전-사후 평가의 수행력을 비교함으로써 이에 대한 유지 효 과를 단계적으로 고려하지 않았다. 향후 연구에서는 유지 효과 의 영향을 다각적으로 고려하고, 중재의 효과성이 유지되기 위 한 방안을 고안해야 할 것이다.

중심 단어 : 작업기억 중재·알츠하이머병·전이 효과·패러다 임·언어 능력.

\section{Ethical Statement}

We explained exactly the purpose and process of this study to all participants in advance. And they agreed to participate in it. This study was approved by the Institutional Review Board (\#HUGSAUD461850).

\section{Acknowledgments}

N/A

\section{Declaration of Conflicting Interests}

There are no conflict of interests.

\section{Funding}

N/A

\section{Author Contributions}

All authors contributed equally to this work. M.L. designed and performed experiments, analyzed data, and wrote the paper; M.L. and B.K. designed and performed experiments in the clinic; M.L. provided statistical analysis and critical revision. Also, the authors discussed the results together and implications and commented on the manuscript at each stage.

\section{ORCID iDs}

Mi Sook Lee https://orcid.org/0000-0001-9255-565X

Bo Seon Kim https://orcid.org/0000-0002-8351-1417

\section{REFERENCES}

Baddeley, A. (2009). Working memory. In Baddeley, A., Eysenck, M. W., \& Anderson, M. C. Memory. New York, NY: Psychology Press.

Belleville, S., Chertkow, H., \& Gauthier, S. (2007). Working memory and control of attention in persons with Alzheimer's disease and mild cognitive impairment. Neuropsychology, 21(4), 458-469.

Benítez-Burraco, A. (2017). Figurative language, language disorders, and language(s) evolution. Frontiers in Psychology, 8, 1713.

Bier, N., Van Der Linden, M., Gagnon, L., Desrosiers, J., Adam, S., Louveaux, S., et al. (2008). Face-name association learning in early Alzheimer's disease: A comparison of learning methods and their underlying mechanisms. Neuropsychological Rehabilitation, 18(3), 343-371.

Borella, E., Carretti, B., \& de Beni, R. (2008). Working memory and inhibition across the adult life-span. Acta Psychologica, 128(1), 33-44.

Borella, E., Carretti, B., Riboldi, F., \& de Beni, R. (2010). Working memory training in older adults: Evidence of transfer and maintenance effects. Psychology and Aging, 25(4), 767-778.

Carretti, B., Borella, E., \& de Beni, R. (2007). Does strategic memory training improve the working memory performance of younger and older adults? Experimental Psychology, 54(4), 311-320.

Carretti, B., Borella, E., Fostinelli, S., \& Zavagnin, M. (2013a). Benefits of training working memory in amnestic mild cognitive impairment: Specific and transfer effects. International Psychogeriatrics, 25(4), 617-626.

Carretti, B., Borella, E., Zavagnin, M., \& de Beni, R. (2013b). Gains in language comprehension relating to working memory training in healthy older adults. International Journal of Geriatric Psychiatry, 28(5), 539546.

Chein, J. M. \& Morrison, A. B. (2010). Expanding the mind's workspace: Training and transfer effects with a complex working memory span task. Psychonomic Bulletin and Review, 17(2), 193-199.

Chow, T. W., Binns, M. A., Freedman, M., Stuss, D. T., Ramirez, J., Scott, C. J., et al. (2008). Overlap in frontotemporal atrophy between normal aging and patients with frontotemporal dementias. Alzheimer Disease and Associated Disorders, 22(4), 327-335.

Conway, A. R. A., Kane, M. J., \& Engle, R. W. (2003). Working memory capacity and its relation to general intelligence. Trends in Cognitive Sci- 
ences, 7(12), 547-552.

Dahlin, E., Neely, A. S., Larsson, A., Bäckman, L., \& Nyberg, L. (2008). Transfer of learning after updating training mediated by the striatum. Science, 320(5882), 1510-1512.

Kane, M. J., Hambrick, D. Z., Tuholski, S. W., Wilhelm, O., Payne, T. W., \& Engle, R. W. (2004). The generality of working memory capacity: A latent-variable approach to verbal and visuospatial memory span and reasoning. Journal of Experimental Psychology: General, 133(2), 189-217.

Kang, Y. W., Chin, J. H., Na, D. L., Lee, J. H., \& Park, J. S. (2000). A normative study of the Korean version of Controlled Oral Word Association Test (COWAT) in the elderly. Korean Journal of Clinical Psychology, 19(2), 385-392.

Kim, B. S. \& Lee, M. S. (2019). Scoring method according to severity of impaired discourse production in normal elderly, amnestic mild cognitive impairment, and dementia. Journal of Special Education and Rehabilitation Science, 58(1), 347-365.

Kim, J. W., Kang, Y., \& Yoon, J. H. (2015). Category norms for Korean adults age 55 to 74. Communication Sciences and Disorders, 20(4), 559569.

Klingberg, T. (2012). Is working memory capacity fixed? Journal of Applied Research in Memory and Cognition, 1(3), 194-196.

Laws, K. R., Adlington, R. L., Gale, T. M., Moreno-Martínez, F. J., \& Sartori, G. (2007). A meta-analytic review of category naming in Alzheimer's disease. Neuropsychologia, 45(12), 2674-2682.

Lee, M. S. (2017). Linguistic predictors of cognition in aging. Journal of Special Education and Rehabilitation Science, 56(2), 237-262.

Lee, M. S. \& Kim, B. S. (2019). Characteristics of word fluency in healthy aging and Alzheimer's disease. Audiology and Speech Research, 15(2), 135-143.

Lezak, M. D., Howieson, D. B., Loring, D. W., Hannay, H. J., \& Fischer, J. S. (2004). Neuropsychological Assessment. (4th ed.). New York, NY: Oxford University Press.

Li, S. C., Schmiedek, F., Huxhold, O., Röcke, C., Smith, J., \& Lindenberger, U. (2008). Working memory plasticity in old age: Practice gain, transfer, and maintenance. Psychology and Aging, 23(4), 731-742.

McArdle, J. J. \& Prindle, J. J. (2008). A latent change score analysis of a randomized clinical trial in reasoning training. Psychology and Aging, 23(4), 702-719.

McKhann, G., Drachman, D., Folstein, M., Katzman, R., Price, D., \& Stadlan, E. M. (1984). Clinical diagnosis of Alzheimer's disease: Report of the NINCDS-ADRDA Work Group under the auspices of Department of Health and Human Services Task Force on Alzheimer's disease. Neurology, 34(7), 939-944.

Morris, J. C. (1993). The Clinical Dementia Rating (CDR): Current version and scoring rules. Neurology, 43(11), 2412-2414.

Morrison, A. B. \& Chein, J. M. (2011). Does working memory training work? The promise and challenges of enhancing cognition by training working memory. Psychonomic Bulletin and Review, 18(1), 46-60.

Nee, D. E., Berman, M. G., Moore, K. S., \& Jonides, J. (2008). Neuroscientific evidence about the distinction between short- and long-term memory. Current Directions in Psychological Science, 17(2), 102-106.

Olson, I. R. \& Jiang, Y. (2004). Visual short-term memory is not improved by training. Memory and Cognition, 32(8), 1326-1332.

Peach, R. K. \& Shapiro, L. P. (2012). Cognition and Acquired Language Disorders: An Information Processing Approach. (1st ed.). St. Louis, MO: Mosby.

Shin, J. (2008). Phoneme and syllable frequencies of Korean based on the analysis of spontaneous speech data. Communication Sciences and Disorders, 13(2), 193-215.

Shin, J. (2010). Phoneme and syllable frequencies based on the analysis of entries in the Korean dictionary. Communication Sciences and Disorders, 15(1), 94-106.

Shipstead, Z., Hicks, K. L., \& Engle, R. W. (2012). Cogmed working memory training: Does the evidence support the claims? Journal of Applied Research in Memory and Cognition, 1(3), 185-193.

St Clair-Thompson, H., Stevens, R., Hunt, A., \& Bolder, E. (2010). Improving children's working memory and classroom performance. Educational Psychology, 30(2), 203-219.

Sung, J. E. (2011). The reliability and validity of short-term and working memory pointing tasks developed for clinical populations with speech and language disorders. Communication Sciences and Disorders, 16(2), 185-201.

Thompson, T. W., Waskom, M. L., Garel, K. L. A., Cardenas-Iniguez, C., Reynolds, G. O., Winter, R., et al. (2013). Failure of working memory training to enhance cognition or intelligence. PLoS One, 8(5), e63614.

Unsworth, N. \& Engle, R. W. (2007). On the division of short-term and working memory: An examination of simple and complex span and their relation to higher order abilities. Psychological Bulletin, 133(6), 1038-1066.

Westerberg, H., Jacobaeus, H., Hirvikoski, T., Clevberger, P., Ostensson, M. L., Bartfai, A., et al. (2007). Computerized working memory training after stroke-A pilot study. Brain Injury, 21(1), 21-29.

Yeom, T., Park, Y., Oh, K., Kim, J., \& Lee, Y. (1992). A Manual for K-WAIS. Seoul: Korea Psychology.

Zimmermann, N., Netto, T. M., Amodeo, M. T., Ska, B., \& Fonseca, R. P. (2014). Working memory training and poetry-based stimulation programs: Are there differences in cognitive outcome in healthy older adults? NeuroRehabilitation, 35(1), 159-170. 